\title{
CONTRIBUIÇÃO À AVALIAÇÃO DA CRIAÇÃO DE SIMBOLOGIAS PARA MAPEAMENTOS GEOMORFOLÓGICOS SOBRE IMAGENS ANÁGLIFOS GEORREFERENCIADAS EM AMBIENTE SIG
}

\author{
Leticia Giuliana Paschoal $^{(\mathrm{a})}$, Fernando de Morais ${ }^{(\mathrm{b})}$ \\ (a) Departamento de Geografia, Universidade Federal de Tocantins, Campus de Porto Nacional. E-mail: \\ leticiagiulinapaschoal@gmail.com \\ (b) Departamento de Geografia, Universidade Federal de Tocantins, Campus de Porto Nacional. E-mail: \\ morais@uft.edu.br
}

\section{Eixo: GEOTECNOLOGIAS E MODELAGEM ESPACIAL EM GEOGRAFIA FÍSICA}

\section{Resumo}

\begin{abstract}
Esse trabalho tem como objetivo avaliar a criação de simbologias sobre imagens anáglifos em meio digital, de forma a permitir a identificação de feições que compõem o relevo e a simultânea vetorização dos mesmos, em ambiente computacional. Para tanto, foi selecionado um fragmento da bacia hidrográfica do rio Palmeiras (TO), inserida no contexto das mais significativas paisagens cársticas do Brasil central. A metodologia constitui-se em gerar imagens anáglifos com base em pares de fotografias aéreas digitais, na escala 1:45.000, do ano de 1964, com auxílio do aplicativo StereoPhoto Maker. Em seguida, as potencialidades de seu aproveitamento na construção dos mapas geomorfológicos, com ênfase na identificação e vetorização das feições encontradas na área foram avaliadas em ambiente SIG. Os resultados apontam para o fato de que os procedimentos adotados nesse trabalho fornecem subsídios para que quaisquer dados de morfografia e morfogênese, vinculados ao processo operacional do mapeamento geomorfológico seja realizado.
\end{abstract}

Palavras chave: cartografia digital, imagem tridimensional, feições geomorfológicas, StereoPhoto Maker, técnicas de mapeamentos.

\section{Introdução}

Avanços tecnológicos ocorridos na área de Sensoriamento Remoto têm proporcionado à comunidade científica novas formas de ampliar a aquisição de informações sobre o espaço geográfico. Nesse sentido, a obtenção de dados do relevo que compõem o mapeamento geomorfológico, também tem passado por transformações.

O método tradicional de fotointerpretação, ainda muito utilizado por pesquisadores de Geociências, em específico por aqueles que recorrem à geração de mapeamentos geomorfológicos para a identificação das formas e entendimento de sua dinâmica sobre a superfície terrestre, ocorre de maneira totalmente analógica: a fotointerpretação com base em pares de fotografias aérea se utiliza de estereoscópios, de bolso ou mesa, para a visualização tridimensional do relevo; em seguida, a retirada dos dados de estereoscopia deve ocorrer em papel poliéster, que compõem overlays, que devem ser digitalizados e georreferenciados com precisão sobre a base cartográfica, para que posteriormente, ocorra o processo de vetorização das informações contidas nos mesmos. Essas diversas etapas tornam o processo de 
mapeamento geomorfológico, muitas vezes, exaustivo, sobretudo se a área em análise for extensa e a escala de detalhe.

Frente à forma tradicional de obtenção de dados sobre as feições do relevo, surge a possibilidade de observação de imagens tridimensionais e a realização de sua fotointerpretação diretamente na tela do computador, devidamente georreferenciadas em ambiente SIG. Essa técnica se fundamenta na geração de imagens anáglifos, com base em pares de fotografias aéreas digitais, e tem se mostrado uma alternativa viável e otimizadora de tempo, se comparado à forma tradicional de obtenção de dados sobre as feições do relevo.

De acordo com Souza e Oliveira (2012), o método anáglifo constitui-se da sobreposição dos pares de fotografias aéreas em ambiente computacional, nas cores vermelho e azul, que observados por meio de um filtro, no caso, óculos com lentes de cores complementares, popularmente conhecidos como óculos 3D, permitem que mecanismos cerebrais gerem a sensação de tridimensionalidade aos olhos humanos.

Diante do exposto, o presente trabalho tem como objetivo avaliar a criação de simbologias sobre imagens anáglifos georreferenciadas em ambiente computacional. Essa metodologia permite a simultânea identificação de feições que compõem o relevo e a vetorização dos mesmos, em ambiente SIG. Para aplicação desta técnica, o recorte submetido à avaliação corresponde a um fragmento espacial inserido no contexto das mais significativas paisagens cársticas da porção central brasileira, localizado no setor Sul da bacia hidrográfica do rio Palmeiras, Sudeste do estado do Tocantins.

As imagens anáglifos foram geradas de acordo com as orientações de Souza e Oliveira (2012), com auxilio do aplicativo StereoPhoto Maker em ambiente computacional e o posterior georreferenciamento e vetorização das feições do relevo observadas, seguiram as orientações técnicas de Paschoal et al. (2010), que se utiliza do software ArcGis. Em seguida foi apresentado o fragmento espacial da imagem anáglifo gerada com base em pares de fotografias aéreas digitais da bacia hidrográfica do rio Palmeiras, na escala de 1:45.000, do ano de 1964, e as respectivas vetorizações das feições do relevo em ambiente SIG, para que as potencialidades da união entre essas duas técnicas fossem debatidas quanto ao seu aproveitamento na construção dos mapas geomorfológicos.

\section{Material e métodos}

A realização desse trabalho fez uso de pares de fotografias aéreas em formato digital, datadas do ano de 1966, na escala de 1:45.000, adquiridas junto à Companhia de Pesquisa de Recursos Minerais - CPRM (Serviço Geológico do Brasil); aplicativo StereoPhoto Maker, de uso livre, versão 5.10, disponível para download no endereço: http://stereo.jpn.org/eng/stphmkr/; óculos para visualização em 3D, com lentes nas cores vermelho e azul; microcomputador e programa ArcGis. 


$\begin{gathered}\text { XVII Simpósio Brasileiro } \\ \text { de Geografia Física Aplicada }\end{gathered}$
$\begin{aligned} & \text { I Congresso Nacional } \\ & \text { de Geografia Física }\end{aligned}$

O mapeamento geomorfológico de detalhe fornece subsídios para uma análise minuciosa dos elementos que compõem o relevo, sejam eles naturais ou derivados da ação antrópica. Avanços tecnológicos ocorridos na área de Sensoriamento Remoto têm viabilizado a aquisição de parte dos dados que compõem esse mapeamento, fazendo com que ele dinamize a coleta de informações sobre o espaço geográfico que antes ocorriam de forma analógica.

O anáglifo é uma imagem tridimensional que permite a visão estereoscópica quando observada por meio de óculos com lentes de cores diferentes (vermelho e azul). Essa imagem é formada a partir da inserção de pares de fotografias aéreas no ambiente computacional do aplicativo StereoPhoto Maker (SOUZA e OLIVEIRA, 2012). Complementar às orientações técnicas sugeridas por Souza e Oliveira (2012), enfatiza-se que para que esse aplicativo seja utilizado com êxito, é preciso fazer com que os arquivos digitais dos pares de fotografias aéreas, que muitas vezes resultam de aerolevantamentos realizados no sentido Norte-Sul, Sul-Norte ou Leste-Oeste, sejam rotacionados de forma a fazer com que a sobreposição das imagens fique disposta de Oeste para Leste. Após esse ajuste, o par de fotografias aéreas deverá ser inserido no sistema Stereo Photo Maker, que o exibirá em sua tela principal (FIGURA $1)$.

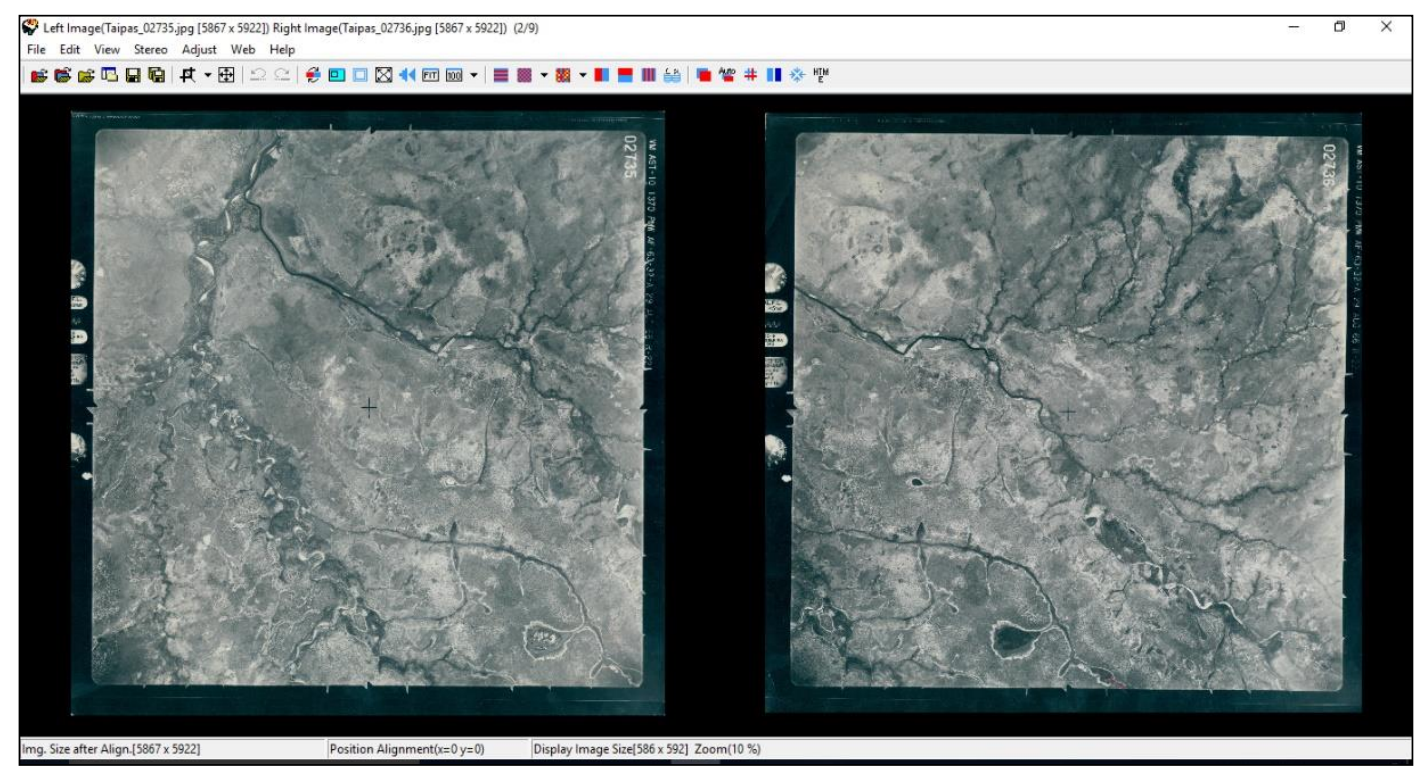

FIGURA 1 - Par estereoscópico de fotografias aéreas aberta simultaneamente na janela principal do aplicativo StereoPhoto Maker.

Para inserir o par de fotografias aéreas que serão parcialmente sobrepostas e darão origem a imagem anáglifo, na janela principal do aplicativo, deve-se clicar no menu File >Open Left/Right Images. É por esse motivo que as imagens devem ser previamente rotacionadas no sentido Oeste-Leste; para que no sistema possa ser inserido primeiro a imagem da esquerda e, em seguida, a da direita.

Posteriormente para que as fotografias sejam parcialmente sobrepostas, é necessário ativar a opção Optimized Anaglyph (disponível no menu Color Anaglyph). Em seguida a ferramenta Auto Alingment deve ser empregada, para que o programa ajuste a sobreposição e o anáglifo seja criado (Figura 2), que 
XVII Simpósio Brasileiro

de Geografia Fisica Aplicada

I Congresso Nacional

de Geografia Física

\section{OS DESAFIOS DA GEOGRAFIA FÍSICA NA FRONTEIRA DO CONHECIMENTO \\ Instituto de Geociências - Unicamp \\ Campinas - SP \\ 28 de Junho à 02 de Julho de 2017}

deverá ser salva em extensão .tiff (File > Save Stereo Image), gerando assim, um arquivo independente que poderá ser georreferenciado.

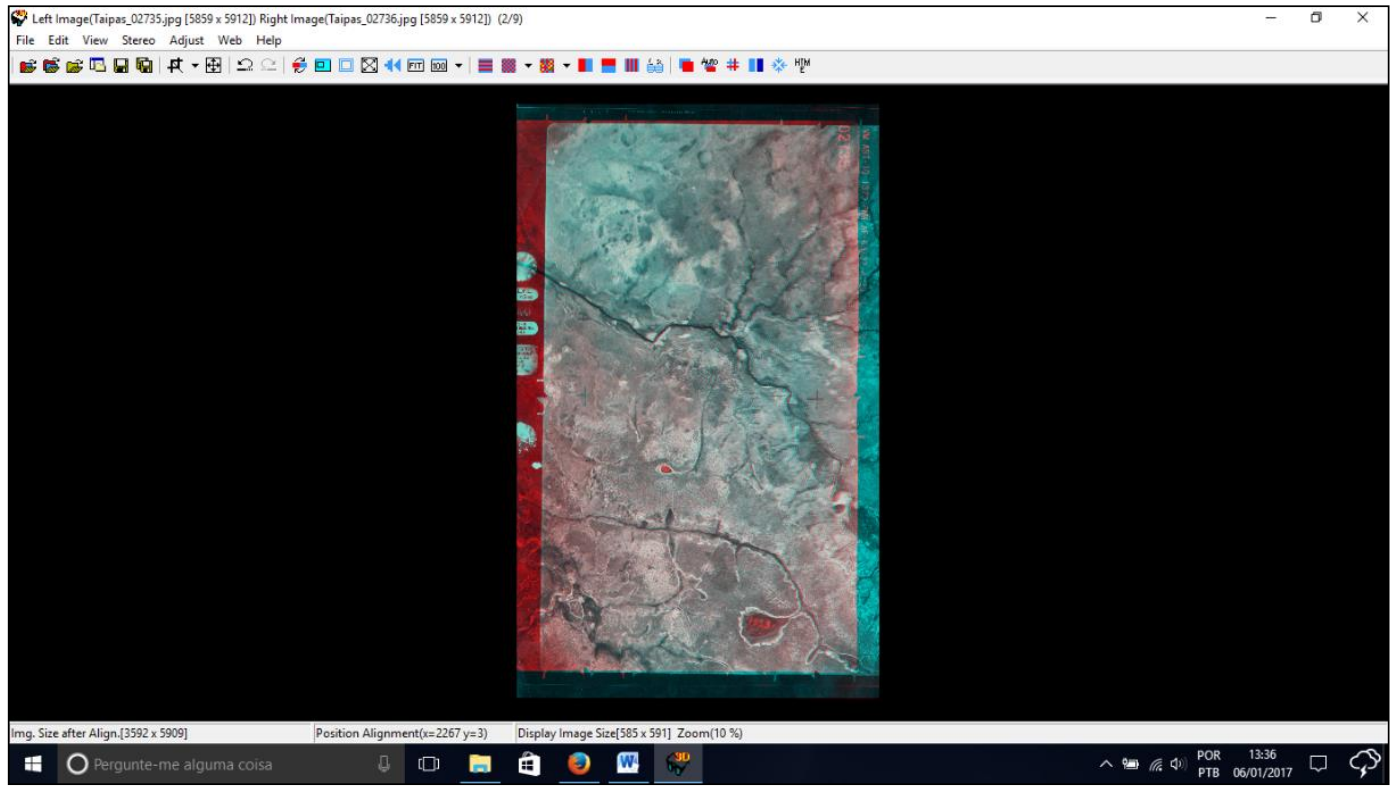

FIGURA 2 - Imagem anágligo.

Outra informação complementar à técnica proposta por Souza e Oliveira (2012) e que visa atender às necessidades da pesquisa, é que antes do georreferenciamento da imagem anáglifo, essas devem ser rotacionadas novamente de acordo com a orientação de seu aerolevantamento. Esse procedimento visa fazer com que o Norte da base cartografráfica e das imagens geradas coincidam, o que permitirá identificar pontos de controle correlatos entre eles e o seu posterior georreferenciamento. Porém, ao rotacionar a imagem anáglifo para outro ângulo, durante o georreferenciamento, essas perdem sua estereoscopia, que só reaparece quando a tela do projetor, em ambiente SIG, for rotacionada novamente no sentido de deixar as imagens anáglifos no ângulo em que foram geradas, ou seja, com as imagens de Oeste para Leste.

Em seguida, as feições do relevo foram identificadas e vetorizadas seguindo as orientações técnicas de Paschoal et al. (2010), que discorre sobre a possíbilidade de criar e modificar símbolos pré-existentes no diretório contido no programa ArcMap, tornando-os aptos a representar as mais diversas feições do relevo, como é o caso de diferentes tipos de vertentes e interflúvios; feições derivadas da ação das águas correntes; modelados antrópicos; litologias, entre outros.

As feições do relevo que compõem o fragmento da carta geomorfológica a ser gerada à partir do uso dessa técnica, foram classificadas em: pontos, linhas e áreas. Assim, as dolinas de dissolução mapeadas no setor Sul da bacia hidrográfica do rio Palmeiras (TO), foram representadas por meio de áreas. As rupturas topográficas, suaves e ingremes; os diferentes tipos de fundos de vale, com dinâmica predominantemente erosiva ou deposicional; e os processos erosivos, identificados no estágio de 
desenvolvimento denominado "sulco", foram gerados a partir de shapefiles configurados como linhas. Os tipos de vertentes, côncavas ou convexas, colos topográficos, caimentos topográficos e condutos identificados na area, foram classificados como pontos.

Conforme destaca Paschoal et al. (2012), é importante salientar que a criação de shapfiles destinados a representação pontual de determinados elementos, como os condutos, tipos de vertentes e caimentos topográficos, foram criados por meio de shapefiles do tipo "linhas", o que permitiu a obtenção do resultado desejado em caráter amostral. Dentro do shape "linha" é possível ocultar a linha e trabalhar apenas com o tipo de finalização da mesma (ponto), que pode variar de uma simples seta ao símbolo desejado para a concretização do mapeamento. Esta alternativa mostrou-se bastante pertinente, pois há símbolos, como os supra-citados, que necessitam acompanhar a direção em que os processos ocorrem sobre o relevo, fato esse que não ocorre se utilizado um shape "ponto", que apresenta todos os símbolos dispostos na mesma direção. A disposição de símbolos que seguem uma única orientação é válida, por exemplo, para indicar colos topográficos, que não se relacionam com a direção em que ocorre esse processo.

Com base nesta classificação e seguindo as orientações de Paschoal et al. (2010), criou-se um shapefile no ArcCatalog do ArcMap, para cada elemento de representação do relevo, que após ter sua simbologia criada e salva, possibilitou a elaboração e estruturação de um banco de dados dos mesmos no programa. A simbologia utilizada nos mapeamentos geomorfológicos se pautou principalmente na adaptação das propostas de Tricart (1965), CNRS (1971), Verstappen e Zuidan (1975), Simon (2007) e Paschoal et al. (2010).

\section{Resultados e discussões}

Um fragmento espacial estratégico foi selecionado na área situada próxima ao exultório da bacia hidrográfica do rio Palemiras (TO), a fim de identificar feições erosivas localizadas, formas de vertentes, interflúvios, fundos de vale, feições antrópicas, além daquelas vinculadas ao esculpimento do relevo cárstico (FIGURA 3). 

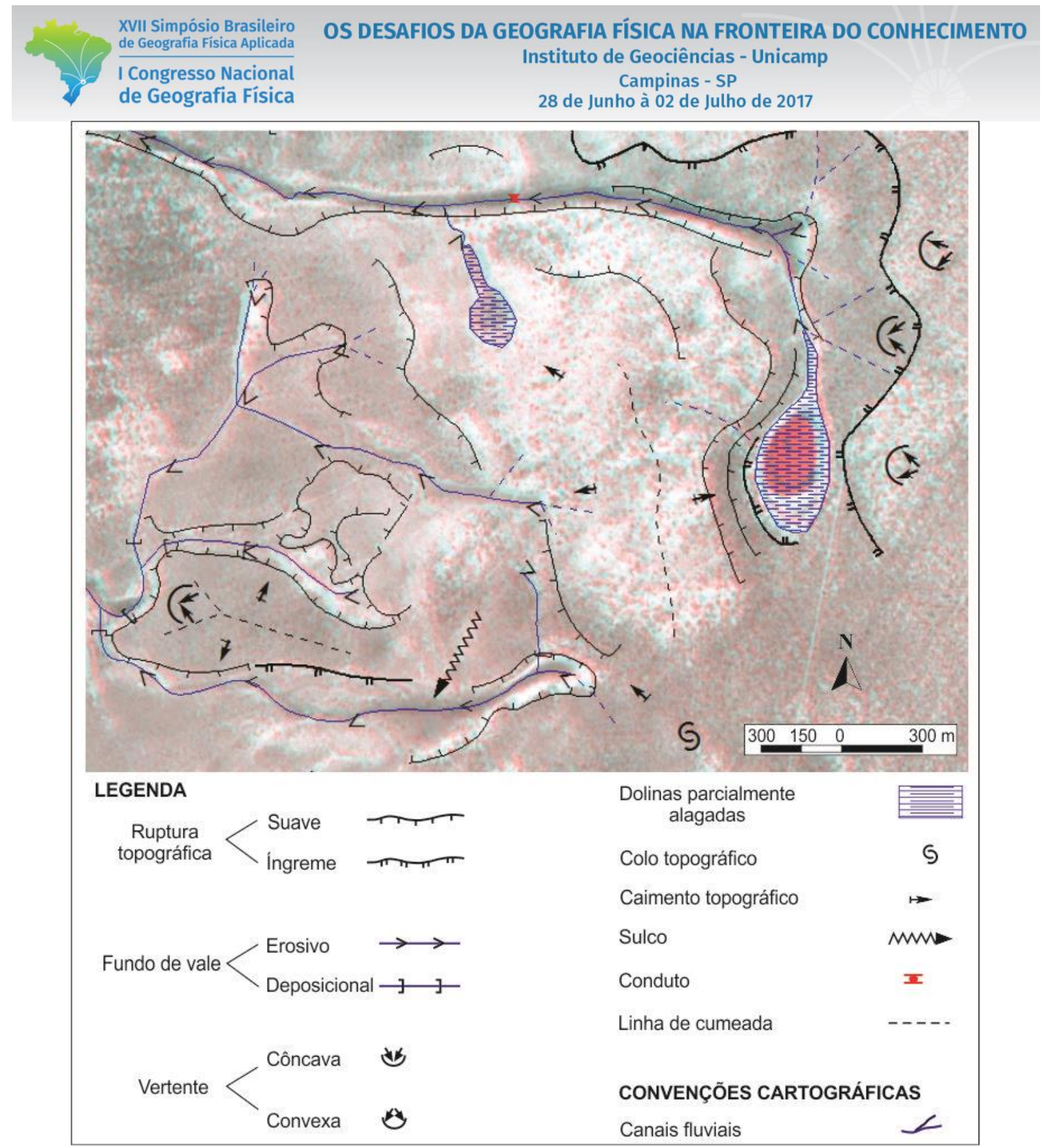

FIGURA 3 - Características da rede de drenagem, formas de vertentes, rupturas topográficas e das áreas de desenvolvimento do relevo carstico, verificadas a partir das imagens anáglifos vetorizadas diretamente na tela do computador, utilizando-se do programa ArcMap. Organização: Paschoal, L.G. (2017).

A análise da imagem anáglifo (Figura 3), permitiu constatar que os canais fluviais, próximo às nascentes dos rios possuem dinâmica erosiva, apresentando-se levemente encaixados na paisagem de pequena amplitude altimetrica. Foi possível ainda, identificar o desenvolvimento de relevo cárstico em alguns pontos, que vieram a se constituir em áreas de nascentes, onde se formaram dolinas de dissolução diante da reação ocorrida entre a água de superfície e o substrato rochoso da area, que se configuram como rochas carbonáticas do Grupo Bambuí.

A visão tridimensional fornecida pela imagem anagligo permitiu constatar que as vertentes identificadas no setor são predominantemente convexas, típicas do clima tropical, no qual o período chuvoso, associado à temperaturas elevadas, resultam em formas arredondadas do relevo. As vertentes côncavas 
foram identificadas, sobretudo, próximas às áreas de nascente, onde a litologia se apresenta mais friável, constituindo-se em caminhos preferenciais para o escoamento das águas de superfície em direção aos rios. Assim, o modelado das vertentes, pode ser classificado de maneira satisfatória.

Feições vinculadas a processos erosivos também foram passíveis de ser identificadas e mapeadas. No setor Sul da imagem, em uma área onde a cobertura vegetal apresenta-se menos densa, foi possível classificar um sulco sobre um seguimento côncavo da vertente.

A estereoscopia com base nos anáglifos também permitiu a identificação e posterior vetorização de feições que marcam as descontinuidades no declive, denominadas rupturas topográficas. As rupturas marcam a evolução da vertente, ou seja, evidenciam que ao longo dela, ocorre um processo erosivo diferenciado. Essas puderam ser classificadas com base nos ângulos de quebra das vertentes em suave ou íngreme. Tais feições podem ter sua origem em fatores naturais, como em diferentes materiais que compõe a litologia, ou então podem estar atrelados ao tipo de uso e ocupação da terra empregado pelo homem, que as dinamizam, acelerando sua evolução, bem como pode fazer surgir novas rupturas.

Foi identificado também um colo topográfico existente sobre o divisor de águas da bacia do rio Palmeiras. A existência desta feição indica uma fragilidade litológica que, naquele ponto do relevo, encontra-se mais susceptível a reagir ao intemperismo químico que as áreas circunvizinhas, denotado pelo maior desgaste erosivo do terreno.

Ainda na figura 3, foi possível identificar uma feição de origem antrópica, que implantou um conduto, possibilitando a passagem de uma estrada que se sobrepôs ao rio, intervindo na dinâmica do escoamento das águas fluviais.

\section{Considerações finais}

A metodologia adotada de identificação de feições do relevo por meio da interpretação de imagens anáglifos, seu posterior georreferenciamento e a vetorização dessas feições a partir de simbologias criadas no diretório do ArcMap, conforme descritos nesse trabalho, demonstrou boa operacionalidade. Assim, torna-se possível a adoção da fotointerpretação em meio digital, para a aquisição de dados de morfografia e morfogênese, que devem compor os mapeamentos geomorfológicos, conforme sugere Tricart (1965).

A fotointerpretação dos anáglifos diretamente na tela do computador permitiu o mesmo nível de detalhamento de quando interpretados por meio de estereoscópios de espelho. Em casos específicos, como quando o relevo apresenta baixa amplitude altimétrica, o estereoscópio de bolso ainda constituise em um grande aliado no processo de fotointerpretação, por fornecer um exagero vertical maior. Também há de se considerar que devido às distorções de borda que as fotografias aéreas apresentam, a parte central dos anáglifos é a que apresenta melhor a tridimensionalidade da imagem. 
Para que as imagens anáglifos não percam a visão tridimensional após o georreferenciamento, a sugestão de rotacionamento do projeto em ambiente SIG, para o ângulo em que as imagens anáglifos foram criadas, seguindo o sentido Oeste - Leste, é de fundamental importância. Esse procedimento não é exclusivo para o ArcMap, tornando-se válido para a inserção das imagens anáglifos em qualquer outro programa que permita a vetorização das feições do relevo após o seu georreferenciamento.

Vinculado ao relevo cárstico existente na área em estudo, essa metodologia, aplicada à fotografias aéreas na escala de 1:45.000, permitiu a identificação de dolinas, porém, feições de dimensões menores, como campos de lapiás ou verrugas, necessitam de trabalho de campo para serem melhor individualizadas.

O domínio das técnicas descritas nesse trabalho tende a contribuir com a otimização do tempo de pesquisadores que se dedicam a elaboração de mapas geomorfológicos, que podem substituir as etapas de fotointerpretação analógica e marcação das simbologias representativas do relevo sobre overlays de poliéster, que seriam posteriormente escaneados, georreferenciados e vetorizados, por uma técnica mais dinâmica e que fornece resultados similares.

A utilização do ArcMap como instrumento para elaboração de cartas geomorfológicas demonstrou resultados positivos quanto aos aspectos visuais das simbologias geradas, o que permite formular considerações a respeito da cena mapeada em questão.

Outro ponto positivo dessa técnica se deve ao fato do StereoPhoto Maker ser um software gratuito, além de ser de fácil manuseio. Os óculos especiais, com lentes nas cores vermelho e azul, são de baixíssimo custo, podendo ser feito inclusive com papel celofane das respectivas cores. O software a ser usado no georreferenciamento pode ser qualquer um que esteja disponível na Universidade ou Centro de Pesquisa onde se desenvolve a pesquisa (mapeamento), desde que permita a elaboração das simbologias adequadas.

Os procedimentos adotados e descritos nesse trabalho fornecem subsídios para que quaisquer dados de morfografia e morfogênese, vinculados ao processo operacional do mapeamento geomorfológico seja realizado. Torna-se importante salientar que esse artigo não visa esgotar os recursos dos programas citados, constituindo-se em uma contribuição às discussões acerca do assunto.

\section{Agradecimentos}

Este artigo faz parte da pesquisa de Pós-Doutorado intitulada "Avaliação da criação de morfologias antropogênicas em áreas cársticas e a sua relação com a dinâmica do uso da terra", realizada na Universidade Federal de Tocantins (UFT), Campus de Porto Nacional. Assim, os autores agradecem ao Programa PNPD/CAPES pelo suporte financeiro concedido à realização desta pesquisa e ao Programa Pós-Graduação em Geografia da UFT por torná-la viável. 


\section{Bibliografia}

CNRS Legende pour la carte geomorphplogique de la France au 1:50.000. Traduzido e adaptado para o espanhol por Serrat, et al., 1976, Centre National de La Recherche Scientifique, 66 p. 1971.

PASCHOAL, L. G.; CONCEIÇÃO, F. T.; CUNHA, C. M. L. Utilização do ArcGis 9.3 na elaboração de simbologias para mapeamentos geomorfológicos: Uma aplicação na área do Complexo Argileiro de Santa Gertrudes/SP. 2010. In: VIII Simpósio Nacional de Geomorfologia. Recife: 2010, 13 p.

SIMON, A. L. H. A dinâmica de uso da terra e sua interferência na morfohidrografia da bacia do Arroio Santa Bárbara - Pelotas (RS). Dissertação (Mestrado em Geografia). Instituto de Geociências e Ciências Exatas, Universidade Estadual Paulista, Rio Claro, 2007.

SOUZA, T. A. de.; OLIVEIRA, R. C. Avaliação da potencialidade de imagens tridimensionais em meio digital para o mapeamento geomorfológico. Revista GeoNorte. Manaus/AM, Edição Especial, v.2, n.4, p.1348 - 1355, 2012.

TRICART, J. Principes et méthodes de la géomorphologie. Paris: Masson, 1965.

VERSTAPPEN, H. T.; ZUIDAM, R. A. van. ITC System of geomorphological survey. Manual ITC Textbook, Netherlands: Enschede, 1975, v. 1, cap. 8. 